\title{
Lupus anticoagulants in systemic lupus erythematosus: prevalence and clinical associations
}

\author{
K Padmakumar, Ram R Singh, R Rai, Anand N Malaviya, Anil K Saraya
}

\begin{abstract}
The prevalence of lupus anticoagulant (LAC) and its relation with reported clinical associations has been determined in 55 patients with systemic lupus erythematosus (SLE) from northern India who were studied prospectively. Kaolin clotting time was used to screen for LAC, which was detected in seven (13\%) of the patients. Significant associations were found between LAC and thrombotic events, onset of disease at an early age, and disease of shorter duration. No statistically significant association could be found between LAC and recurrent abortions, pulmonary hypertension, thrombocytopenia, and neurological manifestations.
\end{abstract}

It is concluded that LAC is a useful marker for a subset of patients with SLE at risk of thromboembolic events.

The existence of spontaneously acquired anticoagulant activity in systemic lupus erythematosus (SLE) has been known since 1952. There has been a recent interest in this so-called lupus anticoagulant (LAC) ${ }^{2}$ with the appearance of several major studies. ${ }^{3-6}$ The main reason for the interest seems to be the possible association of LAC with thromboembolic events. ${ }^{4-8}$ Its association with other clinical manifestations, like miscarriage or pulmonary hypertension, remains controversial. ${ }^{6-11}$ Moreover, the prevalence of LAC has been found to vary widely in different series. ${ }^{3-6}$

This study was therefore carried out to establish the prevalence and clinical correlates of LAC in SLE seen at this centre.

Clinical Immunology Section, Department of Medicine,

and Hematology Unit,

Department of Patholosy, All-India Institute of Medical Sciences, New Dellhi, India

K Padmakumar

R Rai

A N Malaviya

A $\mathrm{K}$ Saraya

Department of

Immunology,

Sanjay Gandh

Postoraduate Institute of

Medical Sciences,

Lucknow, India

R R Singh

Correspondence to:

Correspondence to:

Clinical Immunology Section,

Department of Medicine,

Sciences, New Delhi 110029

Sciences
India.

Accepted for publication

10 January 1990 ing oral contraceptives and other agents whict might affect the kaolin clotting time (KCT) were similarly excluded. At the time of study 48 patients were taking low dose prednisolone (less than $10 \mathrm{mg}$ in 37 and $10-15 \mathrm{mg}$ in 11 patients). Seven patients were taking only antimalarial drugs and paracetamol.

After a detailed clinical evaluation the following laboratory investigations were carried out: (a) immunological tests for antinuclear antibody, antibodies against extractable nuclear antigens, including Sm, nRNP, SS-A, and SS-B, rheumatoid factor, $\mathrm{C}$ reactive protein, and $\mathrm{C} 3$ concentrations; (b) a coagulation profile including bleeding time ${ }^{13}$ and clotting tests ${ }^{14}$ - prothrombin time, prothrombin consumption index, activated partial thromboplastin time, Russell's viper venom time with inosithin, and KCT. The presence of LAC was confirmed using mixing patterns with KCT, as described by Exner et al. 15

Patients with LAC were followed up for a minimum of two years. Detailed clinical and laboratory tests were done every three months. Testing for LAC was not repeated on patients with a negative test on the first occasion.

A $\chi^{2}$ test was used for statistical analysis.

\section{Results}

Patients were divided into two subgroups based on the results of the KCT: group A $(n=48)$ with normal KCT and group B (n=7, 13\%) with prolonged KCT (having LAC).

Table 1 shows the cumulative incidence of clinical and immunological indices in these 55 patients and a comparison of the two subgroups. There was a statistically higher incidence of thrombosis in patients with LAC.

There was also a statistically significant difference in the age of onset and duration of illness between the two groups. Patients with LAC were younger and had a shorter duration of illness than those without it. The incidence of LAC was $63 \%(5 / 8)$ in juvenile SLE compared with $4 \%(2 / 47)$ in adult patients. No significant differences between other clinical, immunological, and haematological indices and LAC were seen.

Table 2 shows the detailed coagulation profile of seven patients with LAC. In these seven patients activated partial thromboplastin time was prolonged in five (71\%), Russell's viper venom time in two $(29 \%)$, prothrombin time in two (29\%), and Russell's viper venom time with inosithin in one (14\%) patient. The figure shows the mixing pattern of KCT in seven patients with positive LAC. Three patients (Nos 2, 4, and 7) had classical LAC with mixing pattern of type I-that is, the prolonged KCT could not be brought to normal by addition of normal plasma. In two patients (Nos 1 and 3) the KCT 
Table 1 Cumulative incidence of clinical and inmounological indices in 55 patients with systemic lupus erythematosus. Results are given as the number of patients

\begin{tabular}{|c|c|c|c|c|}
\hline & $\begin{array}{l}\text { All patients } \\
(n=55)\end{array}$ & $\begin{array}{l}L A C^{*} \text { negative } \\
(n=48)\end{array}$ & $\begin{array}{l}\text { LAC positive } \\
(n=7)\end{array}$ & $\begin{array}{l}\text { Significance } \\
\text { (p value) }\end{array}$ \\
\hline $\begin{array}{l}\text { Mean (SD) age of onset of illness (years) } \\
\text { (range) } \\
\text { Mean (SD) duration of disease (years) }\end{array}$ & $\begin{array}{l}24 \cdot 9(10 \cdot 6) \\
(9-60) \\
2 \cdot 0(1 \cdot 7)\end{array}$ & $\begin{array}{l}29 \cdot 3(10 \cdot 5) \\
(9-60) \\
2 \cdot 1(1 \cdot 8)\end{array}$ & $\begin{array}{l}16 \cdot 3(6 \cdot 8) \\
(13 \cdot 27) \\
1 \cdot 3(0 \cdot 9)\end{array}$ & $\begin{array}{l}<0.01 \\
<0.01\end{array}$ \\
\hline $\begin{array}{l}\text { Clinical feature } \\
\text { Malar rash } \\
\text { Photosensitivity } \\
\text { Polyarthritis } \\
\text { Oral ulcers } \\
\text { Raynaud's phenomenon } \\
\text { Myositis } \\
\text { Pleuropericarditis } \\
\text { Convulsions } \\
\text { Psychosis } \\
\text { Neurological deficit } \\
\text { Minor neuropsychiatric illness } \\
\text { Nephritis } \\
\text { Hypertension } \\
\text { Thrombocytopenia } \\
\text { Thrombotic events } \\
\text { Pulmonary hypertension } \\
\text { Recurrent abortions } \\
\text { ANA positive } \\
\text { Anti-ENA* positive } \\
\text { Low C3 concentration (normal } 0.7-1 \cdot 2 \mathrm{~g} / \text { ) }\end{array}$ & $\begin{array}{r}38 \\
22 \\
48 \\
27 \\
22 \\
7 \\
18 \\
8 \\
5 \\
4 \\
7 \\
29 \\
5 \\
7 \\
4 \\
2 \\
2(35) \dagger \\
54 \\
18(39) \ddagger \\
32(45) \ddagger\end{array}$ & $\begin{array}{r}33 \\
19 \\
42 \\
23 \\
21 \\
7 \\
17 \\
6 \\
4 \\
2 \\
5 \\
25 \\
5 \\
5 \\
1 \\
2 \\
1(33) \dagger \\
47 \\
17(33) \ddagger \\
26(38) \neq\end{array}$ & $\begin{array}{l}5 \\
3 \\
6 \\
4 \\
1 \\
0 \\
1 \\
2 \\
1 \\
2 \\
2 \\
4 \\
0 \\
2 \\
3 \\
0 \\
1(2) \dagger \\
7 \\
1(6) \ddagger \\
6\end{array}$ & $\begin{array}{l}\text { NS } \\
\text { NS } \\
\text { NS } \\
\text { NS } \\
\text { NS } \\
\text { NS } \\
\text { NS } \\
\text { NS } \\
\text { NS } \\
\text { NS } \\
\text { NS } \\
\text { NS } \\
\text { NS } \\
\text { NS } \\
<0 \cdot 5 \\
\text { NS } \\
\text { NS } \\
\text { NS } \\
\text { NS } \\
\text { NS }\end{array}$ \\
\hline
\end{tabular}

*AC=lupus anticoagulant; ANA=antinuclear antibody; ENA=extractable nuclear antigen.

+ Number of married patients is given in parentheses.

$\neq$ Numbers in parentheses indicate the number of patients tested where it is less than the total patients in that group.

Table 2 Coagulation profile of seven patients with prolonged kaolin clotting time

\begin{tabular}{|c|c|c|c|c|c|c|c|c|c|c|c|c|c|c|}
\hline \multirow{2}{*}{$\begin{array}{l}\text { Patient } \\
\text { No }\end{array}$} & \multirow{2}{*}{$\begin{array}{l}\text { Platelet } \\
\text { count } \\
\left(\times 10^{\circ} / l\right)\end{array}$} & \multirow{2}{*}{$\begin{array}{l}P T^{*} \\
(s)\end{array}$} & \multirow{2}{*}{$\begin{array}{l}P C I^{*} \\
(\%)\end{array}$} & \multicolumn{2}{|c|}{$A P T T^{*}(s)$} & \multicolumn{2}{|c|}{$R V V T^{*}(s)$} & \multirow{2}{*}{$\begin{array}{l}\text { RVVT } \\
\text { with } \\
\text { inosithin }\end{array}$} & \multicolumn{5}{|c|}{$K C T^{*}(s)$} & \multirow{2}{*}{$\begin{array}{l}B T^{*} \\
(\min )\end{array}$} \\
\hline & & & & $P t^{*}$ & $P t / N^{*}$ & $P t$ & $P t / N$ & & $\begin{array}{l}N P^{*} \\
100 \%\end{array}$ & $\begin{array}{l}N P(75 \%) \\
+P P^{*} \\
(25 \%)\end{array}$ & $\begin{array}{l}N P(50 \%) \\
+P P \\
(50 \%)\end{array}$ & $\begin{array}{l}N P(25 \%) \\
+P P \\
(75 \%)\end{array}$ & $\begin{array}{l}P P \\
(100 \%)\end{array}$ & \\
\hline $\begin{array}{l}1 \\
2 \\
3 \\
4 \\
5 \\
6 \\
7\end{array}$ & $\begin{array}{l}140 \\
350 \\
310 \\
240 \\
200 \\
220 \\
320\end{array}$ & $\begin{array}{l}14 \\
19 \\
12 \\
13 \\
32 \\
13 \\
13\end{array}$ & $\begin{array}{l}40 \\
59 \\
42 \cdot 5 \\
43 \\
25 \\
60 \\
45\end{array}$ & $\begin{array}{r}54 \\
51 \\
45 \\
47 \\
111 \\
32 \\
54\end{array}$ & $\begin{array}{l}1.38 \\
1.30 \\
1.25 \\
1.15 \\
2.02 \\
0.89 \\
1.54\end{array}$ & $\begin{array}{l}15 \\
14 \\
14 \\
21 \\
73 \\
13 \\
14\end{array}$ & $\begin{array}{l}1.15 \\
1.00 \\
1.07 \\
1.5 \\
5.21 \\
1.00 \\
1.08\end{array}$ & $\begin{array}{l}12 \\
11 \\
11 \\
12 \\
16 \\
11 \\
10\end{array}$ & $\begin{array}{r}88 \\
94 \\
92 \\
114 \\
110 \\
106 \\
104\end{array}$ & $\begin{array}{l}120 \\
153 \\
123 \\
146 \\
473 \\
130 \\
180\end{array}$ & $\begin{array}{l}123 \\
152 \\
130 \\
153 \\
470 \\
130 \\
184\end{array}$ & $\begin{array}{l}125 \\
141 \\
154 \\
166 \\
616 \\
126 \\
228\end{array}$ & $\begin{array}{l}136 \\
156 \\
170 \\
176 \\
529 \\
121 \\
253\end{array}$ & $\begin{array}{l}3.5 \\
5 \\
3.0 \\
3.5 \\
4.0 \\
4.0 \\
6.5\end{array}$ \\
\hline
\end{tabular}

*PT=prothrombin time (normal range (NR) 11-14 s); PCI=prothrombin consumption index (NR 0-30\%); APTT=activated partial thromboplastin time (NR 35-45 s); $\mathbf{P t}=$ patient; $\mathbf{N}=$ normal control; $\mathbf{R V V T}=\mathbf{R u s s e l l}$ 's viper venom time (NR 10-15 s; with inosithin NR 9-13 s); $\mathrm{KCT}=\mathrm{kaolin}$ clotting time (NR $60-120 \mathrm{~s}$ ); $\mathrm{BT}=\mathrm{bleeding}$ time (NR 2-45 min); NP=normal plasma; $P$ P= patient's plasma.
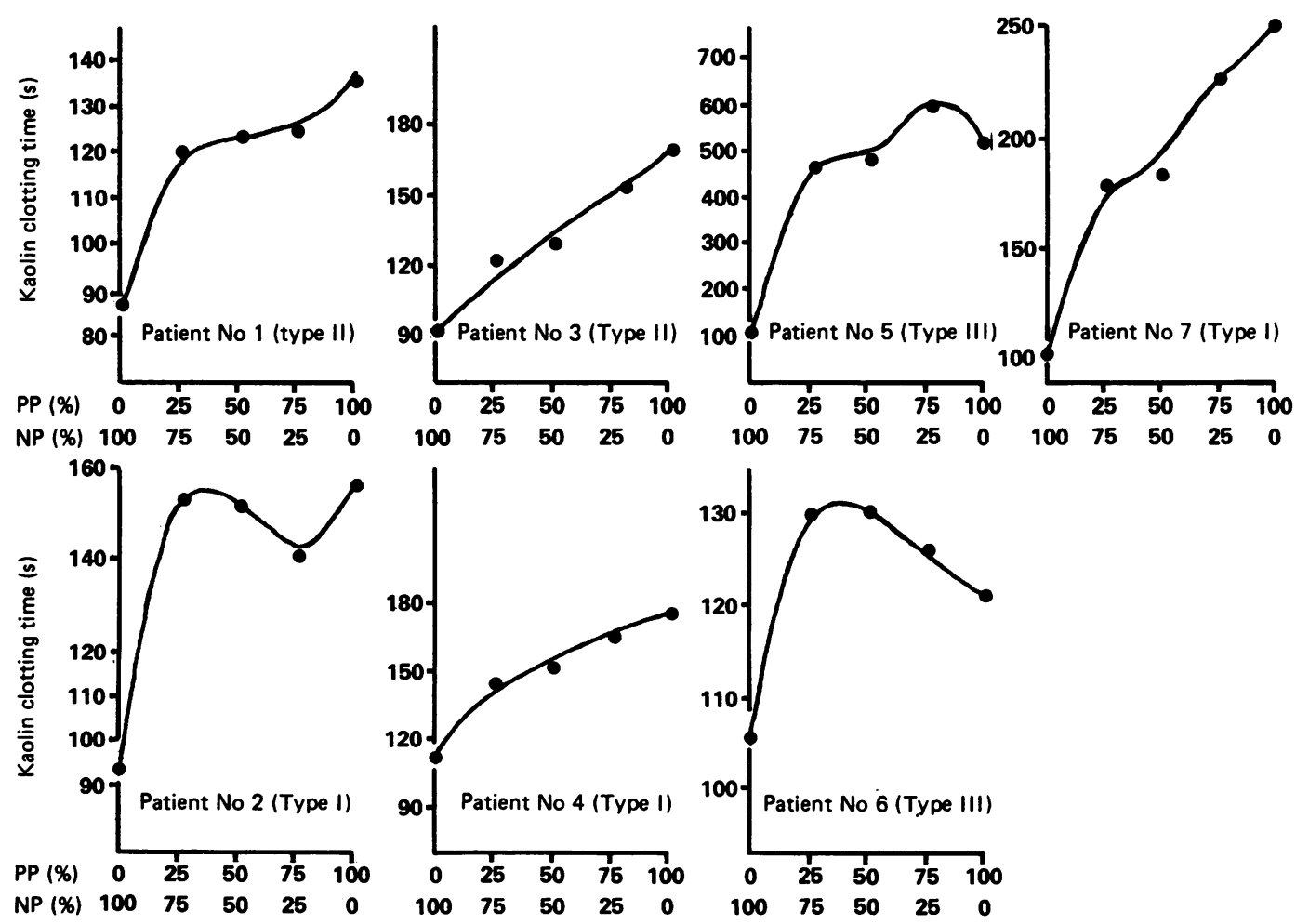

Mixing pattern of kaolin clotting time in seven patients with positive lupus anticoagulant. $P P=$ patient's plasma; $N P=$ normal plasma. 
Table 3 Comparison of coagulation profile in patients with systemic lupus erythematosus without (group $A$ ) and with (group B) lupus anticoagulant. Results are given as means $(S D)$

\begin{tabular}{|c|c|c|c|c|}
\hline Test & $\begin{array}{l}\text { Normal } \\
\text { range }\end{array}$ & $A(n=48)$ & $B(n=7)$ & p Value \\
\hline $\begin{array}{l}\text { Bleeding time (min) } \\
\text { Prothrombin time (s) } \\
\text { Prothrombin consumption index (\%) } \\
\text { APTT* (s) } \\
\text { RVVT* (s) } \\
\text { RVVT with inosithin (s) } \\
\text { Kaolin clotting time (s) }\end{array}$ & $\begin{array}{l}2-4 \cdot 5 \\
11-14 \\
0-30 \\
35-45 \\
10-15 \\
9-13 \\
60-120\end{array}$ & $\begin{array}{l}4 \cdot 27(2 \cdot 76) \\
12 \cdot 61(1 \cdot 05) \\
42 \cdot 07(13 \cdot 18) \\
43 \cdot 60(8 \cdot 45) \\
14 \cdot 1(2 \cdot 85) \\
10 \cdot 60(1 \cdot 30) \\
84 \cdot 81(18 \cdot 86)\end{array}$ & $\begin{array}{l}4 \cdot 21(1 \cdot 19) \\
16 \cdot 57(7 \cdot 18) \\
44 \cdot 93(11 \cdot 95) \\
56 \cdot 29(25 \cdot 28) \\
23 \cdot 43(22 \cdot 02) \\
11 \cdot 36(1 \cdot 95) \\
220 \cdot 14(142 \cdot 57)\end{array}$ & $\begin{array}{l}\text { NS } \\
\text { NS } \\
\text { NS } \\
\text { NS } \\
\text { NS } \\
\text { NS } \\
<0 \cdot 05\end{array}$ \\
\hline
\end{tabular}

*APTT = activated partial thromboplastin time; RVVT $=$ Russell's viper venom time.

approached the upper limit of normal and had a type II mixing pattern, which might mean the presence of associated factor deficiency. In the other two patients (Nos 5 and 6) the KCT of the mixture of normal and patient plasma was greater than either on their own. Therefore, it was consistent with a type III mixing pattern, indicating the presence of cofactor deficiency.

Table 3 compares the coagulation profiles in groups A (normal KCT) and B (prolonged KCT). No significant difference was found in various coagulation indices in these two patient groups.

The clinical features and follow up of the seven patients with LAC are summarised below. The clinical features purported to be associated with LAC, including deep vein thrombosis, thrombocytopenia, and neuropsychiatric manifestations were seen in two, two, and four cases respectively. Of the two married patients in the LAC positive group, one had seven abortions and the other had one.

Six of these patients were followed up for two years after the detection of LAC. Patient 1 developed focal proliferative lupus nephritis. In patient 2 deep vein thrombosis and thrombocytopenia responded to prednisolone and aspirin. She developed diffuse proliferative lupus nephritis with crescents and, later on, renal failure. There was no response to high dose corticosteroids and cyclophosphamide pulse therapy. Patient 3, who initially presented with menorrhagia, developed diffuse proliferative lupus nephritis. She responded to cyclophosphamide pulse therapy. Patient 4 developed self-limiting episodes of tinnitus, giddiness, and deafness. She also had features of hysterical neurosis. Her cerebellar ataxia subsided after prednisolone treatment. ${ }^{16}$ Patient 5 developed mesangial lupus nephritis and features of diffuse cerebral dysfunction in the form of severe headaches, seizures, transient blurring of vision, white spots in visual field, memory dysfunction, abnormal feeling, and apraxia. These manifestations responded well to prednisolone. Patient 7 had another two abortions during the two year follow up period despite continuous treatment with high dose prednisolone and low dose aspirin.

\section{Discussion}

A knowledged of the prevalence of LAC is important because of its reported clinical association with thrombotic events, recurrent abor- tions, and pulmonary hypertension. The prevalence of LAC in SLE has been found to vary from $0.4 \%$ to $65 \%$ in different reports. ${ }^{3-6}$ This difference may reflect the differing sensitivities and lack of standardisation of various assays, ${ }^{17} 18$ fluctuation in the level of LAC with disease activity or treatment, ${ }^{19} 20$ and differing criteria of patient selection.

The sensitivity for detection of LAC is improved by the use of platelet poor plasma and a low concentration of thromboplastin, ${ }^{15}$ and the preferred test at present is KCT. ${ }^{1821}$ Using this test in our 55 patients with SLE, we found an LAC prevalence of $13 \%$. This prevalence, though comparable with that reported by many other workers, ${ }^{22}$ was much less than that $(65 \%)$ reported by Exner et $a l^{15}$ using the same test. They studied 17 patients referred for haematological problems, however, suggesting a selection bias. Some underestimation in our study could not be ruled out as most patients had received immunosuppressive treatment in the past. None of our patients was receiving cytotoxic drugs and high dose corticosteroids at the time of study, however. Until the various screening tests are standardised and definite criteria laid down for detection of LAC, the exact prevalence of LAC cannot be confirmed.

The prevalence of LAC was very high in younger patients $(63 \%$ in juvenile SLE as compared with $4 \%$ in patients aged more than 16). A similar observation has been made by Lechner. $^{24}$

The patients with LAC presented with a shorter duration of illness than those without it. This might be due to the presence of a more severe illness in these patients, necessitating a visit to a tertiary hospital early in the course of illness.

A comparison of the clinical profile in the two subgroups shows a higher incidence of thrombosis in those with LAC $\chi^{2}=397 ; p<0.05$ ). Previous studies have also shown a strong association between LAC and thrombotic events. ${ }^{4825}$ For the other clinical manifestations purported to be associated with LAC (current abortions, pulmonary hypertension, thrombocytopenia, and neurological manifestations), ${ }^{3-11}$ however, we found no significant correlation, possibly owing to the small sample size. Petri et al, similarly, found no significant association between LAC and either miscarriage or pulmonary hypertension. ${ }^{6}$ One patient (No 3 ) in our study had a bleeding diathesis with no known cause. This prevalence $(1 / 7(14 \%))$ is higher than that reported by Shapiro and Thiagrajan, who found a prevalence of bleeding ascribable exclusively to LAC of less than $0.6 \%$ in a series of 320 patients with LAC. ${ }^{22}$

A good response in patients with SLE and LAC, who were treated with one or more of steroids, salicylates, or anticoagulants-for example, warfarin, has been reported. ${ }^{71026}$ Both our patients with deep vein thrombosis responded to steroids and low dose aspirin. High dose corticosteroids and low dose aspirin could not prevent a ninth abortion in patient No 7, however. Randomised, double blind trials are needed to establish the proper guidelines for the drug treatment of patients with LAC. 
We thank Mr Ram Kishan of the haematology unit for his technical help.

1 Conley C L, Hartmann R C. A hemorrhagic disorder caused by circulating anticoagulant in patients with disseminated lupus erythematosus. $f$ Clin Invest 1952; 31: 621-2.

2 Feinstein D I, Rapaport S I. Acquired inhibitors of blood coagulation. Prog Hemost Thromb 1972; 1: 75-95.

3 Derksen R H W M, Kater L. Lupus anticoagulant: revival of an old phenomenon. Clin Exp Rheumatol 1985; 3: 349-57.

4 Boey M L, Colaco C B, Gharavi A E, Elkon K B, Loizou S Hughes G R V. Thrombosis in systemic lupus erythematosus: striking association with the presence of circulating lupus anticoagulant. $\mathrm{Br} \mathrm{Med} \mathcal{f}$ 1983; 287: 1021-3.

5 Derksen R H W M, Bouma B H, Kater L. The prevalence and clinical association of the lupus anticoagulant in
systemic lupus erythematosus. Scand $\mathcal{F}$ Rheumatol 1987; 16: 185-92.

6 Petri M, Rheinschmidt M, Whiting-O'Keefe Q, Hellmann $D$, Corash $L$. The frequency of lupus anticoagulant in systemic lupus erythematosus. Ann Intern Med 1987; 106 : $524-31$.

7 Elias M, Eldor A. Thrombembolism in patients with "lupus" type circulating anticoagulant. Arch Intern Med 1984; 144: $510-5$.

8 Asherson R A, Mackworth-Young C G, Harris E N, Gharavi $A$ E, Hughes G R V. Multiple venous and arterial thromboses associated with the lupus anticoagulant and antibodies to cardiolipin in the absence of SLE. Rhewmatol Int 1985; 5: 91-3.

9 Branch D W, Scott J R, Kochenour N K, Hershgold E. Obstetric complications associated with the lupus antiObstetric complications associated with the

10 Lockshin M D, Druzin M L, Goel S, et al. Antibody to cardiolipin as a predictor of fetal distress or death in cardiolipin as a predictor of fetal distress or death in pregnant patients with systemic

11 Asherson R A, Hackett D, Gharavi A E, Harris E N, Kennedy H G, Hughes G R V. Pulmonary hypertension in systemic lupus erythematosus: a report of three cases. I Rhewmatol 1986; 13: 416-20.

12 Tan E M, Cohen A S, Fries J S, et al. The 1982 revised criteria for the classification of SLE. Arthritis Rheum 1982; 25: 2171-7.
13 Mielke C H, Kaneshiro M M, Mathes I A, Weine J M, Rapaport S I. The standardized Ivy bleeding time and its prolongation by aspirin. Blood 1969; 34: 204-8.

14 Dacie I V, Lewis S M. Practical haematology. 6th ed. Edinburgh: Churchill Livingstone, 1984.

15 Exner T, Rickard $K A$, Kronenberg $H$. A sensitive test demonstrating lupus anticoagulant and its behavioural patterns. Br $\mathcal{J}$ Haematol 1978; 40: 143-51.

16 Singh R R, Prasad K, Kumar A, Misra A, Padmakumar K, Malaviya A N. Cerebellar ataxia in systemic lupus erythematosus. Ann Rhewm Dis 1988; 47: 954-6.

17 Mannucci P M, Canciani M T, Mari D, Meucci P. The varied sensitivity of partial thromboplastin and prothrombin time reagents in the demonstration of lupus-like anticoagulant. Scand $\mathcal{f}$ Haematol 1979; 22: 423-32.

18 Triplett D A, Brandt J T, Kaczor D, Schaeffer J. Laboratory diagnosis of lupus inhibitors: a comparison of the tissue thromboplastin inhibition procedure with a new platelet neutralization procedure. Am f Clin Pathol 1983; 79. 678-82.

19 Lubbe $W$ F, Butler W S, Palmer S J, Liggins G C. Fetal survival after prednisone suppression of maternal lupus anticoan alant. Lancet 1983; i: 1361-3.

20 Schleider M A, Nachman R L, Jaffe E A, Coleman M. A clinical study of the lupus anticoagulant. Blood 1976; 48:

21 Rosove M A, Ismail M, Koziol B J, Runge A, Kasper C K. Lupus anticoagulants with a kaolin clotting time using rabbit brain phospholipid in standard and high concentrations. Blood 1986; 68: 472-8.

22 Shapiro S S, Thiagrajan P. Lupus anticoagulants. In: Spaet T H, ed. Progress in hemostasis and thrombosis. New York: Grune and Stratton, 1982: 263-85.

23 Isenberg D A, Shoenfield Y, Schwartz R S. Multiple serologic reactions and their relationship to clinical activity
in systemic lupus erythematosus. Arthritis Rhevm 1984; 27: in system

24 Lechner K, Pabinger-Fasching I. Lupus anticoagulants and thrombosis. Haemostasis 1985; 15: $254-62$.

25 Mueh J R, Herbst K D, Rapaport S I. Thrombosis in patients with the lupus anticoagulant. Ann Intern Med 1980; 92 156-9.

26 Anonymous. Lupus anticoagulant [Editorial]. Lancet 1984; i: 